\title{
Pan-spectral observing system simulation experiments of shortwave reflectance and long-wave radiance for climate model evaluation
}

\author{
D. R. Feldman ${ }^{1}$, W. D. Collins ${ }^{1,2}$, and J. L. Paige ${ }^{1}$ \\ ${ }^{1}$ Lawrence Berkeley National Laboratory, Earth Sciences Division, Berkeley, CA, USA \\ ${ }^{2}$ University of California-Berkeley, Department of Earth and Planetary Science, Berkeley, CA, USA \\ Correspondence to: D. R. Feldman (drfeldman@lbl.gov)
}

Received: 17 April 2014 - Published in Geosci. Model Dev. Discuss.: 04 June 2014

Revised: 02 April 2015 - Accepted: 11 June 2015 - Published: 02 July 2015

\begin{abstract}
Top-of-atmosphere (TOA) spectrally resolved shortwave reflectances and long-wave radiances describe the response of the Earth's surface and atmosphere to feedback processes and human-induced forcings. In order to evaluate proposed long-duration spectral measurements, we have projected 21 st Century changes from the Community Climate System Model (CCSM3.0) conducted for the Intergovernmental Panel on Climate Change (IPCC) A2 Emissions Scenario onto shortwave reflectance spectra from 300 to $2500 \mathrm{~nm}$ and long-wave radiance spectra from 2000 to $200 \mathrm{~cm}^{-1}$ at $8 \mathrm{~nm}$ and $1 \mathrm{~cm}^{-1}$ resolution, respectively. The radiative transfer calculations have been rigorously validated against published standards and produce complementary signals describing the climate system forcings and feedbacks. Additional demonstration experiments were performed with the Model for Interdisciplinary Research on Climate (MIROC5) and Hadley Centre Global Environment Model version 2 Earth System (HadGEM2-ES) models for the Representative Concentration Pathway 8.5 (RCP8.5) scenario. The calculations contain readily distinguishable signatures of low clouds, snow/ice, aerosols, temperature gradients, and water vapour distributions. The goal of this effort is to understand both how climate change alters reflected solar and emitted infrared spectra of the Earth and determine whether spectral measurements enhance our detection and attribution of climate change. This effort also presents a path forward to understand the characteristics of hyperspectral observational records needed to confront models and inline instrument simulation. Such simulation will enable a diverse set of comparisons between model results from coupled model intercomparisons and existing and proposed satellite instrument measurement systems.
\end{abstract}

\section{Introduction}

The spectrally integrated upwelling top-of-atmosphere radiant energy field comprises the Earth system's total energy balance, and comprehensive comparisons of modelled outgoing long-wave radiation (OLR) and albedo with observationally based estimates of these quantities have led to important constraints on climate models (e.g. Morcrette, 1991; Kiehl et al., 1994). The spectrally resolved energy field spans an additional dimension that contains information regarding the processes that govern that balance. Moreover, it has been demonstrated that infrared spectra contain important information that can be used to test climate models (e.g. Goody et al., 1998), primarily because the spectral signatures of individual forcings and feedbacks can be readily separated, detected, and quantified. Recent work by Roberts et al. (2011) suggest that shortwave spectra also contain independent information about processes that contribute to albedo. Although the separability of processes that contribute to albedo from these spectra has not been addressed formally, Jin et al. (2011) showed the utility of shortwave spectral fingerprints which may be extended to consider spectral separability.

This has motivated the implementation of Observing System Simulation Experiments (OSSEs) based on climate models as a means for exploring the utility of well-posed comparisons between models and measurements. OSSEs are wellestablished techniques for evaluating the scientific and operational value of new instruments proposed for meteorological applications (Arnold and Dey, 1986). The role of OSSEs for climate science is less mature than that of the application to short-term weather forecasting for which they were origi- 
nally developed. The decadal length of climate studies and the necessarily long measurement records that are needed to confront how models predict climate change motivate the development of climate model OSSEs. The forward evaluation of remote-sensing signal sensitivity to uncertain model parametrisations and/or global climate sensitivity contributes to the determination of the value of certain types of remotesensing measurements where the underlying climate signal from the model is known. To that end, it has been recently noted by the Intergovernmental Panel on Climate Change (IPCC) that instrument simulators are valuable in that they can obviate inconsistencies between models and measurements (Flato et al., 2013).

Several investigations have explored direct comparisons between measurements from a variety of existing satellitebased instruments and simulations of those measurements based on various climate model integrations. For example, community-wide efforts have led to the establishment of the Cloud Feedback Model Intercomparison Project Observational Simulator Package (COSP) (Bodas-Salcedo et al., 2011), enabling inline instrument simulations for existing missions including the International Satellite Cloud Climatology Project (ISCCP), the MODerate Resolution Imaging Spectroradiometer (MODIS), CloudSat, and CloudAerosol Lidar and Infrared Pathfinder Satellite Observation (CALIPSO). Results from COSP based on models run in historical mode are then compared to existing measurement records to identify model biases (e.g. Kay et al., 2012; Pincus et al., 2012).

Additionally, there have been efforts to explore how hyperspectral measurements can be utilised for facile measurement-model intercomparison. Huang et al. (2007, 2010a) and Leroy et al. (2008) examined long-wave measurements and radio occultation simulations in detail and have compared the spectral signatures of variations in lapse rate, water vapour, and cloud radiative effects (CREs). The discrepancies in measured and modelled spectra suggest that the agreement in measured and modelled OLR is a result of compensating errors between temperature, water vapour, and cloud structure in the models.

Feldman et al. (2011a, b, 2013) developed climate OSSEs with shortwave spectra. These works showed utility of shortwave spectra for detecting climate change, and found that shortwave measurements are more sensitive to low clouds and changes in frozen surface extent than are long-wave spectral measurements.

Despite the potential utility of using visible, near-infrared, and infrared measurements, the simultaneous utilisation of shortwave reflectance and long-wave radiance spectra to address climate change questions has not been explored in detail to date, despite the numerous studies based on coincident observations of broadband OLR and albedo (e.g. Kiehl and Trenberth, 1997; Hansen et al., 2005; Wielicki et al., 2006; Loeb et al., 2009). The combination of shortwave and longwave hyperspectral measurements could potentially be quite useful in addressing fundamental and unanswered questions related to shortwave cloud and ice feedbacks while simultaneously describing the temperature and water vapour structure of the atmosphere. The ultimate goal of this research area is to develop rigorous observational tests for climate models with a particular focus on using measurements to constrain climate model sensitivity.

Existing hyperspectral infrared measurement systems including the Atmospheric Infrared Sounder (AIRS) (Aumann et al., 2003) and the Infrared Atmospheric Sounding Interferometer (IASI) (Siméoni et al., 1997) can be considered as strong observational constraints. Moreover, hyperspectral shortwave measurements are available from the SCanning Imaging Absorption SpectroMeter for Atmospheric CHartographY (SCIAMACHY) (Bovensmann et al., 1999), and these extensive data records could be useful for measurement-model intercomparison.

This paper presents a versatile tool for simulating spectrally resolved measurements from the near-UV $(300 \mu \mathrm{m})$ to the far-infrared $(50 \mu \mathrm{m})$ and discusses how these measurements can be used to generalise existing OSSE efforts. It demonstrates the rigorous radiometric validation needed to establish comprehensive science traceability studies for planned instruments such as those recommended by the National Research Council's Decadal Survey including CLimate Absolute Radiance and Refractivity Observatory (CLARREO) (Wielicki et al., 2013) and GEOstationary Coastal and Air Pollution Events (GEO-CAPE) (Space Studies Board, 2007). Additionally, the pan-spectral OSSE may be utilised to develop climate model observational tests for evaluating results reported to the Coupled Model Intercomparison Project - Phase 5 (CMIP5) (Taylor et al., 2012) and Phase 6 (CMIP6) (Meehl et al., 2014).

\section{Methodology}

Following Feldman et al. (2011a), we present OSSE calculations of shortwave spectral reflectance and long-wave spectral radiance that simulates spectral measurements based on the climate projections conducted with Community Climate System Model, Version 3.0 (CCSM3) integrations (Collins et al., 2006a; Meehl et al., 2006). The spectral calculations are performed with the MODerate Resolution TRANsmission $\left(\right.$ MODTRAN $^{\mathrm{TM}}$ ) radiative transfer code (Berk et al., 2005). The shortwave and long-wave spectra are calculated from 0.3 to $2.5 \mu \mathrm{m}\left(33333\right.$ to $\left.4000 \mathrm{~cm}^{-1}\right)$ at a $15 \mathrm{~cm}^{-1}$ native resolution, and from 5 to $50 \mu \mathrm{m}\left(2000\right.$ to $200 \mathrm{~cm}^{-1}$ ) at a $1 \mathrm{~cm}^{-1}$ native resolution. The calculations produce top-of-atmosphere (TOA) radiance spectra and upwelling and downwelling direct and diffuse spectral flux (irradiance) fields at each vertical level of CCSM3.

The fields produced in CCSM3 integrations include vertical profiles of atmospheric thermodynamic properties, trace gases, and condensed species on a 26 level hybrid-sigma grid 
extending from the surface to a constant pressure level of $2 \mathrm{hPa}$. CCSM3 has been run at a variety of different horizontal resolutions for the spectral-Eulerian atmospheric dynamical core. The results described here have been computed and archived at T85 resolution representing a triangular truncation of the dynamics at 85 wave numbers and corresponding to a $1.4^{\circ}$ equilateral grid on the Equator. The OSSE, as described by Feldman et al. (2011a), utilises monthly mean values for profiles of temperature, water vapour $\left(\mathrm{H}_{2} \mathrm{O}\right)$, carbon dioxide $\left(\mathrm{CO}_{2}\right)$, ozone $\left(\mathrm{O}_{3}\right)$, methane $\left(\mathrm{CH}_{4}\right)$, nitrous oxide $\left(\mathrm{N}_{2} \mathrm{O}\right)$, trichlorofluoromethane (CFC-11), and dichlorodifluoromethane (CFC-12). Profiles of both liquid and ice cloud area, condensed water content, and effective radius are utilised. The treatment of cloud optics for the spectral simulations in the OSSE is identical to that used by the CCSM3. In the shortwave, the optical properties of liquid and ice clouds vary with wavelength (Hansen and Travis, 1974; Slingo, 1989). In the long wave, liquid and ice clouds are treated as grey bodies where liquid clouds are assigned a constant emissivity and ice clouds are assigned an emissivity that varies with the effective radii diagnosed for the constituent ice crystals. The infrared absorption and scattering by aerosols are not included in the long-wave OSSE; although the direct radiative effects of dust, sulfate, carbonaceous, and sea-salt aerosols are incorporated in the shortwave OSSE.

The treatment of the optical surface properties utilises the MODIS Bi-directional reflectance distribution function (Schaaf et al., 2002) and has been critical for the realism of the shortwave OSSEs (Feldman et al., 2011b) under presentday conditions. The formulation of the land-surface optical reflection reproduces the snow-free and snow-covered bidirectional reflectance properties from MODIS, and it also includes the effects of retreating snow cover on projections of the Earth's future reflectance field. The long-wave portion of the OSSE treats ocean surfaces with unitary emissivity, while land surface emissivity is based on an annually cyclic monthly mean climatology derived from spatial and temporal binning of the MODIS Land Surface Emissivity product (Wan and Zhao-Liang, 1997). By design, the effects of changes in sea-ice extent and snow cover are included in the OSSE calculations, while the effects of future land-use and land-cover change and of changing soil moisture on nearinfrared surface albedos are not.

This OSSE software framework requires multiple calls to the MODTRAN radiative transfer code and the OSSE is quite computationally expensive despite the optimised loadbalancing and intrinsic parallelism of the calculations. Even though it is has been run on a massively parallel NASA HighEnd Computing (HEC) facility, the ratio of OSSE computational time to the computational time to integrate the fully coupled CCSM3 for the 21st Century is approximately 50:1. There are several potential methods to reduce this computational expense, which will be discussed in Sect. 4 .
In support of the IPCC fifth assessment report, modelling centres have undertaken significant efforts to produce a large set of model integrations for CMIP5. A similar infrastructure to the CCSM3 offline hyperspectral calculations was adopted for two climate models. These models were Model for Interdisciplinary Research on Climate (MIROC5) (Watanabe et al., 2010) and Hadley Centre Global Environment Model version 2 Earth System (HadGEM2-ES) (Jones et al., 2011), which lie on the low and high end of the model range of CMIP5 equilibrium climate sensitivities at 2.72 and $4.59^{\circ} \mathrm{K} / 2 \times \mathrm{CO}_{2}$, respectively (Andrews et al., 2012). Simulations were implemented for the first 3 decades of the Representative Concentration Pathway 8.5 (RCP8.5) scenario (Van Vuuren et al., 2011). The fields necessary to perform reflectance and radiance calculations in the OSSE have, unfortunately, only been archived at monthly mean temporal resolution for this scenario. Due to the nonlinearity of radiative transfer, it is challenging to validate offline OSSE calculations with the reported values of albedo and OLR from these models, the latter of which are based on averages of radiation calculations performed with time steps of a few minutes.

\section{Results}

In order to meet the requirement for high-accuracy calculations to support both mission design and climate model evaluation, there has been extensive validation performed on both the long-wave and shortwave OSSE calculations based on CCSM3. As a result, the radiation calculations performed by MODTRAN are fully consistent with those produced by the CCSM3 radiation code, which itself is extensively evaluated against line-by-line models (Collins et al., 2006b; Oreopoulos and Mlawer, 2010). While the shortwave OSSE calculations from MODTRAN have already been extensively validated against CCSM3 all-sky and clear-sky albedo (Feldman et al., 2011a), the long-wave fields are a new and critical feature to the OSSE, representing the first time that the hyperspectral climate change signal has been simulated and validated across the entire shortwave and long-wave energy budget of the climate system.

Long-wave validation of the two codes was performed using a comparison of TOA OLR. Differences between the two radiative transfer schemes are less than $1 \%$ for both clearand all-sky conditions and arise from several factors. These factors include the contrasting treatments of clouds as vertically extended non-isothermal layers in MODTRAN versus infinitely thin isothermal objects in CCSM3 together with the contrasting solutions to the radiative equations using eight discrete-ordinate streams in MODTRAN versus two streams in CCSM3. Figure 1a, b show a distribution of the differences between the OLR produced by the OSSE through offline calls to the CCSM3 long-wave radiation code and the OLR produced from the MODTRAN instrument emulator. Figure $1 \mathrm{~b}$ indicates the clear-sky calculations agree to better 

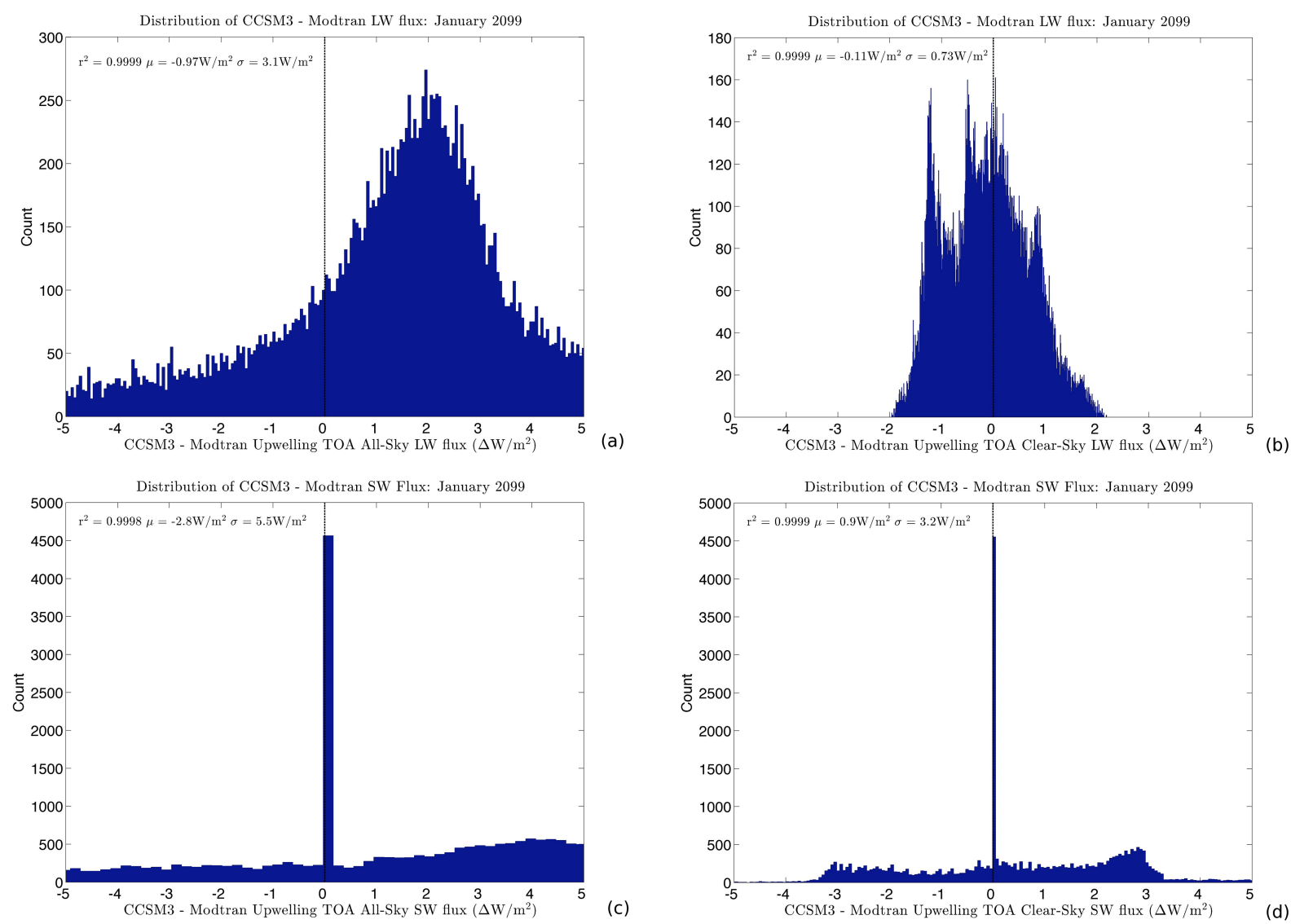

Figure 1. (a) Histogram of all grid points for the difference in all-sky OLR calculated by the CCSM radiative transfer code and by MODTRAN for the 32768 grid boxes from an example month January 2099 for the A2 simulation. Also included are the Pearson correlation coefficient $\left(r^{2}\right)$ and the mean $(\mu)$ and standard deviation $(\sigma)$ of the differences between the two codes. (b) Same as (a) but for clear-sky OLR. (c) Same as (a) but for all-sky shortwave flux. (d) Same as (b) but for clear-sky shortwave flux.

than $2 \mathrm{~W} \mathrm{~m}^{-2}$. Meanwhile, the level of agreement between the all-sky OLR from CCSM3 and MODTRAN is degraded relative to the clear-sky case, as shown in Fig. 1a, with a mean offset of $1 \mathrm{~W} \mathrm{~m}^{-2}$ and a root mean square (rms) value of $3.1 \mathrm{~W} \mathrm{~m}^{-2}$. A closer investigation revealed that the differences in the numbers of streams in the radiative solution and level-layer formulation differences accounted for the allsky discrepancies. This is consistent with the performance of the shortwave reflectance component of the OSSE, though the all-sky agreement between MODTRAN and the Community Atmosphere Model (CAM) component of CCSM3 exhibit less spread because the level-layer formulation discrepancy affects OLR more than albedo. The implication here is that details of vertical formulation of the radiative transfer are critical for competent instrument simulation, especially in the long wave (LW). The agreement between MODTRAN and CAM for shortwave fluxes is shown in Fig. 1c and d with a mean offset of around $3 \mathrm{~W} \mathrm{~m}^{-2}$ in all-sky conditions and $1 \mathrm{~W} \mathrm{~m}^{-2}$ for clear-sky conditions.

Globally averaged long-wave radiance and shortwave reflectance spectra are shown in Fig. 2a for both clear-sky and all-sky conditions at the beginning of the integration. This figure demonstrates many of the complementary features, due to a number of climate-relevant processes, in these two spectral ranges, including two high-transmittance features in the visible and the mid-infrared which are affected by the presence of clouds, but, as shown in Fig. 2b, clear-sky and all-sky differences are of opposite sign between the visible and infrared. Additionally, the spectra indicate a role of water vapour in reducing reflectance in the near-infrared overtone absorption bands between 0.8 and $2.0 \mu \mathrm{m}$ and producing rich spectral structure and decreased infrared radiance between 5 and $8.3 \mu \mathrm{m}$ and 17 and $50 \mu \mathrm{m}$. Prominent greenhouse-gas absorption features are also indicated for $\mathrm{CO}_{2}, \mathrm{O}_{3}, \mathrm{CH}_{4}$, and $\mathrm{N}_{2} \mathrm{O}$.

Figure $2 \mathrm{~b}$ shows the corresponding globally averaged trends in shortwave reflectances and long-wave radiances during the first 50 years of the A2 scenario simulation. Several prominent features can be seen. First, the shortwave reflectances generally increase with the increased aerosol loading projected for the first half of the 21st Century under both clear- and all-sky conditions, and this effect is evident at 

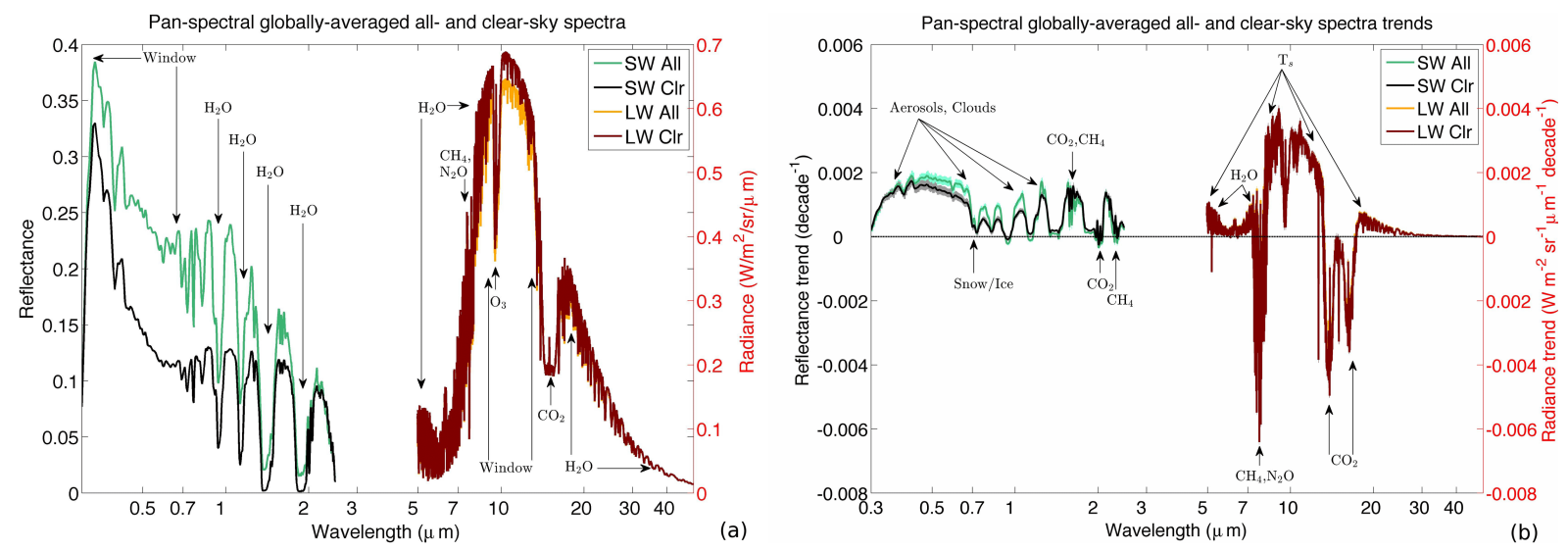

Figure 2. (a) Pan-spectral composite of the globally averaged all-sky and clear-sky shortwave reflectance and long-wave radiance from January 2000 for the A2 simulation. (b) Same as (a) but showing the least-squares trends in shortwave reflectance (in reflectance units per decade) and long-wave radiance (in $\mathrm{W} \mathrm{m}^{-2} \mathrm{sr}^{-1} \mu \mathrm{m}^{-1}$ decade $^{-1}$ ) between 2000 and 2050. Shading indicates $95 \%$ confidence interval of uncertainty in trends.

shorter wavelengths. While much of the spatial and seasonal heterogeneity in shortwave reflectance trends that was identified in Feldman et al. (2011a) is averaged out in the globally and annually averaged trends, the contrast between clear-sky and all-sky reflectance trends gives an indication of the additional increase in reflectance from clouds. Also, the complex spectral structure in the wings of the near-infrared $\mathrm{H}_{2} \mathrm{O}$ overtone absorption bands indicates the potential for shortwave forcing of greenhouse gases, a topic that deserves greater scrutiny (Collins et al., 2006b).

Meanwhile, long-wave radiances show a negative trend around $6.3 \mu \mathrm{m}$ due to greater atmospheric water vapour, positive trends between 8 and $12 \mu \mathrm{m}$ from higher surface skin temperatures, and negative trends between 14 and $16 \mu \mathrm{m}$ from increased absorption in the wings of the mid-infrared $\mathrm{CO}_{2}$ bands. The prescribed increases in $\mathrm{CH}_{4}$ and $\mathrm{N}_{2} \mathrm{O}$ produce prominent negative trends around $7 \mu \mathrm{m}$, while increases in surface and tropospheric temperature are aliased into positive trends in the $\mathrm{H}_{2} \mathrm{O}$ mid- and far-infrared bands.

Figure $3 \mathrm{a}-\mathrm{c}$ show differences in zonally and decadally averaged shortwave reflectance and long-wave radiance spectra for clear-sky and all-sky conditions and cloud radiative effect (CRE) between the decade from 2050 to 2059 and the first decade of the 21 st Century, while Fig. $3 d-f$ show the differences between 2090 and 2099 and the first decade of the 21st Century. Increases in anthropogenic aerosol loading between the decades of the 2000s and the 2050s result in increased clear-sky reflectance at low latitudes and visible and near-infrared wavelengths during that time period. Concurrent changes in the frozen surface coverage decrease reflectance at higher latitudes in the window band but not in the near-infrared. Decadal differences in all-sky shortwave reflectance share some similarities to decadal differences in the clear-sky shortwave reflectance, but vertical striping features in the water-vapour overtone absorption bands are also present and are indicative of the decrease in low-level stratus clouds. Additionally, movement of the InterTropical Convergence Zone (ITCZ) produces a dipole in reflectance near the Equator with diminished striping features across the overtone absorption bands.

The changes in both all-sky and clear-sky long-wave radiance exhibit the spectral features highlighted in Fig. 2b. The only other prominent feature is the polar amplification of surface temperature warming that produces meridional gradients in the window band. Increased cloud cover at high northern latitudes over this period lead to decreases in the radiance across the long-wave spectrum. Additionally, the stratospheric cooling and increased $\mathrm{CO}_{2}$ are prominent around $15 \mu \mathrm{m}$, while increasing $\mathrm{CH}_{4}$ and $\mathrm{N}_{2} \mathrm{O}$ produce significant signals around $7 \mu \mathrm{m}$.

Differences in zonally and decadally averaged shortwave reflectance and long-wave radiance between the start and end of the 21st Century under the A2 emissions scenario are shown in Fig. 3d-f. These spectra show decreased frozen surface extent at high latitudes in visible reflectances and increased water vapour loading leading to lower reflectances in the water vapour overtone bands at $6.3 \mu \mathrm{m}$ and in the farinfrared $\mathrm{H}_{2} \mathrm{O}$ rotational band. All-sky pan-spectral simulations reveal the shifts in storm tracks with striping features in the $\mathrm{H}_{2} \mathrm{O}$ near-infrared overtone bands at mid-latitudes, and they reveal a stronger dipole near the ITCZ near the Equator across the shortwave and long wave.

The CRE changes in Fig. $3 \mathrm{c}$ and $\mathrm{f}$ reveal that significant changes in low-clouds at high latitudes that impact shortwave reflectance and, to a lesser extent, long-wave radiance in both panels. Movement of the ITCZ by the 2090s produces a broadband increase in shortwave reflectance but a broadband decrease in long-wave radiance as shown in Fig. 3f. Such features are much less apparent in the Fig. 3c. 

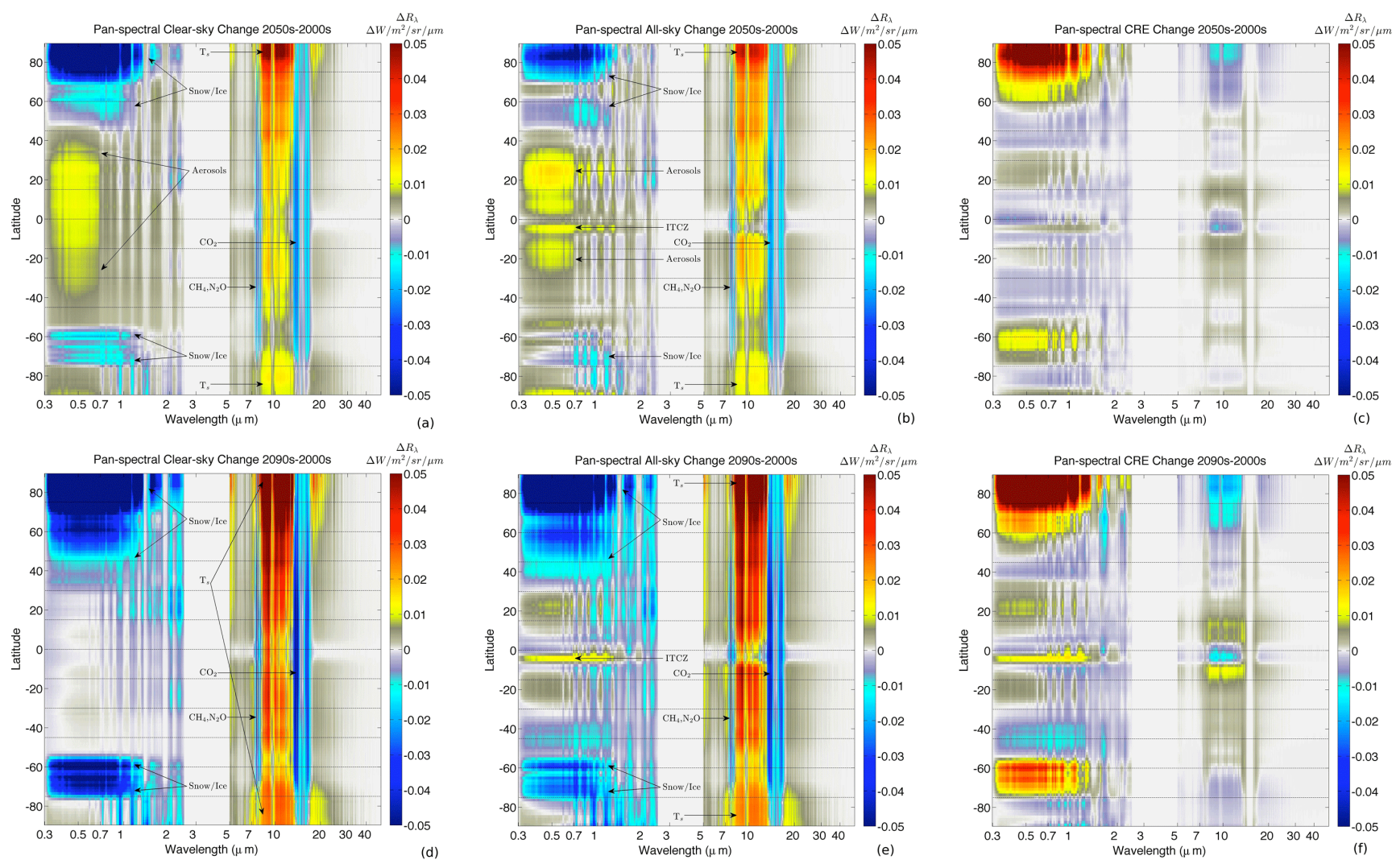

Figure 3. (a) Differences in zonally and decadally averaged pan-spectral clear-sky composite for 2050-2059 and 2000-2009 for the A2 simulation. (b) Same as (a) but plotting differences in all-sky conditions between the 2050s and the 2000s. (c) Differences in cloud radiative effect (CRE) between the 2050s and 2000s. (d) Same as (a) but plotting differences between the 2090s and the 2000s. (e) Same as (d) but plotting all-sky conditions. (f) Same as (c) but plotting differences between the 2090s and 2000s.

OSSEs can also be used for inter-model comparisons. To demonstrate this, we considered the contributions of the MIROC5 and HadGEM2-ES models to the CMIP5 archive. Trend differences in albedo and OLR are shown in Fig. 4ad. In all-sky OLR, as shown in Fig. 4b, trend differences indicate model disagreement in deep convective response in the tropical western Pacific, with HadGEM2-ES showing increased deep convection as compared to MIROC5; however, the difference in the trends changes sign over South America. The clear-sky OLR trend differences, as shown in Fig. 4d, are small but spatially expansive and are due in large part to the water vapour response both in convective and subsidence regions. The MIROC5 model exhibits a water vapour loading response that impacts OLR more than the HadGEM2-ES model.

For climate sensitivity, however, the difference in the processes that affect shortwave radiation of these models is larger than the long wave. Differences in the models' description of sea-ice loss and cloud response at high latitudes, particularly in subsidence regions, have been shown to contribute most significantly to the discrepancy in their equilibrium sensitivities (Andrews et al., 2012). Hyperspectral longwave simulations based on these models have been validated with a bias of $3 \mathrm{~W} \mathrm{~m}^{-2}$ and an rms difference of 0.5 and $3 \mathrm{~W} \mathrm{~m}^{-2}$ for clear-sky and all-sky long wave, respectively, with respect to the model-reported TOA fluxes. For the shortwave simulations, the hyperspectral simulations exhibit an average bias of $0.1 \%$ and an rms difference of 1.5 and $2.2 \%$ for clear-sky and all-sky, respectively, for both models subject to the above-mentioned issues with temporal averaging. Nevertheless, Fig. $4 \mathrm{e}$ and $\mathrm{f}$ indicate that there are numerous differences in the models' response in hyperspectral simulations in subsets of the OSSE spectra from the Arctic and the tropical western Pacific. Both the visible and infrared window spectral regions readily differentiate the two climate model runs, and spectral trends of the model differ significantly. Also, in the Tropical Western Pacific (TWP), the sign of the change in the shortwave visible differs from that of the near-infrared water vapour overtone regions, potentially improving signal detectability, and indicating the potential for spectra to identify processes that contribute to different trends in OLR and albedo. The corollary of this is that longterm spectral trends from measurements can be confronted with the results of a hyperspectral simulator from models to exclude one or more model descriptions of the response to known forcings. It is worth noting that Huang and Ra- 


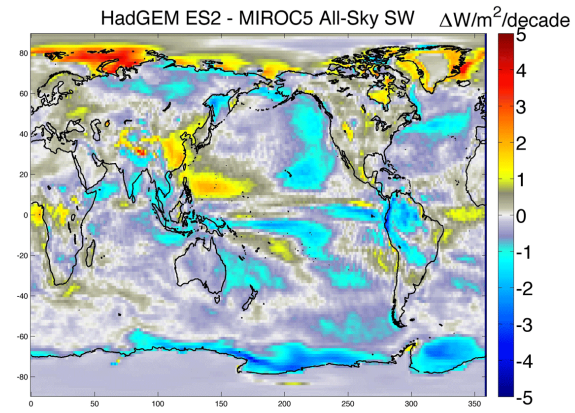

(a)

HadGEM ES2 - MIROC5 Clear-Sky SW $\Delta \mathrm{W} / \mathrm{m}^{2} /$ decade
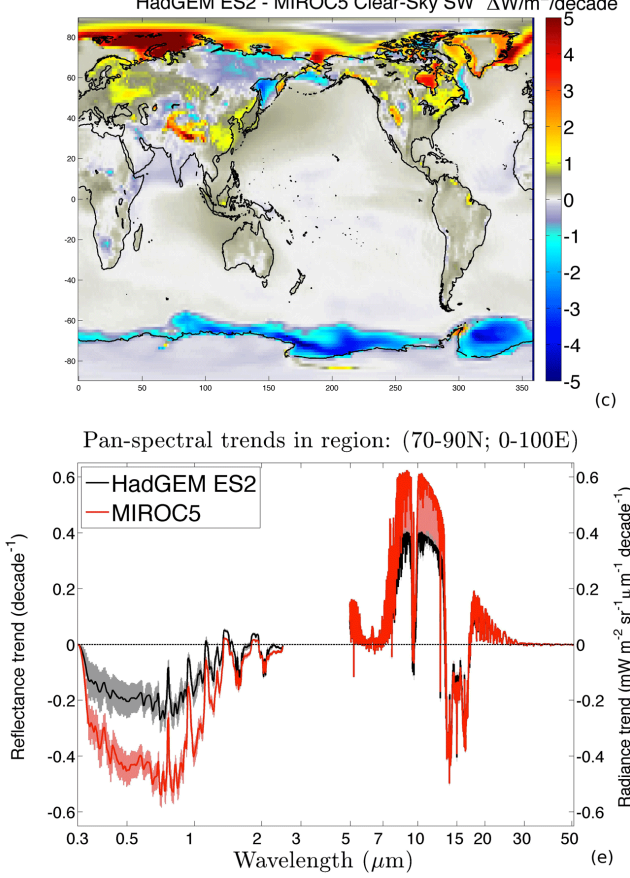

HadGEM ES2 - MIROC5 All-Sky LW $\quad \Delta \mathrm{W} / \mathrm{m}^{2} /$ decade

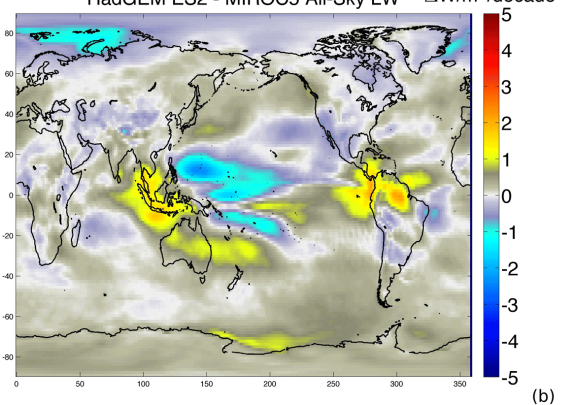

HadGEM ES2 - MIROC5 Clear-Sky LW $\Delta W / \mathrm{m}^{2} /$ decade

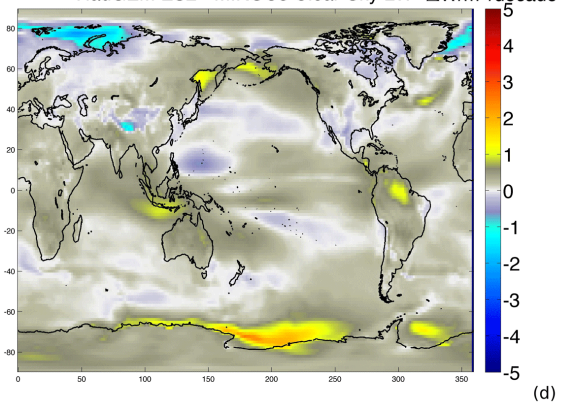

(d)

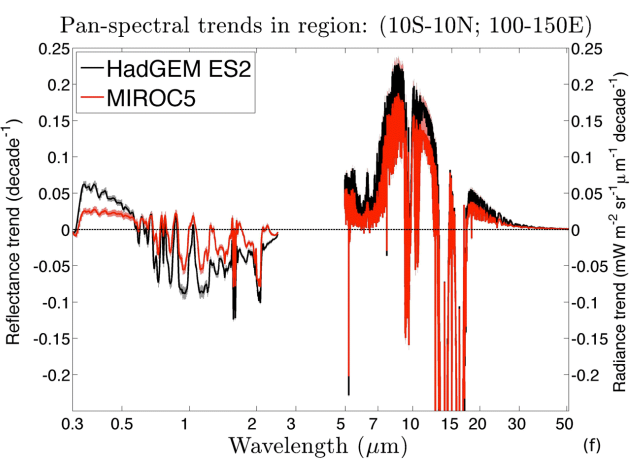

Figure 4. (a) Difference in all-sky shortwave TOA flux trends between HadGEM2-ES and MIROC5 running the RCP8.5 scenario over the period 2005-2035. (b) Same as (a) but for long-wave TOA flux trends. (c) Same as (a) but for clear-sky shortwave TOA flux trends. (d) Same as (a) but for clear-sky long-wave TOA flux trends. (e) Pan-spectral all-sky trends shortwave reflectance and long-wave radiance for the MIROC5 and HadGEM2-ES models derived for the Arctic $\left(70-90^{\circ} \mathrm{N}, 0-100^{\circ} \mathrm{E}\right)$ and (f) for the tropical western Pacific $\left(10^{\circ} \mathrm{S}-10^{\circ} \mathrm{N}\right.$, $\left.100-150^{\circ} \mathrm{E}\right)$.

maswamy (2009) showed that long-wave spectral radiance measurements can disclose detailed climate change signals that would have otherwise been hidden in the model-reported broadband fluxes due to compensating effects. The results here also suggest that such compensation may be occurring in the shortwave as well.

One important caveat to these results, though, is, as mentioned above, the use of monthly mean profiles for simulation. Previous work by Huang and Ramaswamy (2009) found that calculations based on monthly mean profiles rather than instantaneous ones could introduce negative brightness temperature biases between 3 and $4{ }^{\circ} \mathrm{K}$. To test the effect in the shortwave, we modified CCSM such that it reported the fields necessary for the OSSE at $3 \mathrm{~h}$ intervals for a single month, and then compared the results from the OSSE based on a monthly mean profile. We find that the use of monthly mean profiles leads to a positive shortwave reflectance bias RMSE of 0.05 , due to the effect from clouds, but, as was found previously by Roberts et al. (2011), does not appear to impact variability significantly. However, this shortwave is larger than the climate change signal, and modelling centres therefore need to archive the fields necessary for instantaneous radiative transfer calculation to avoid precluding offline diagnoses.

Hyperspectral instrument simulators such as the one presented here enable researchers to explore the spectral dimension of climate change to understand how various processes contribute to changes in albedo and OLR. The large number of data points generated by this pan-spectral OSSE provide numerous opportunities for measurement-model inter- 

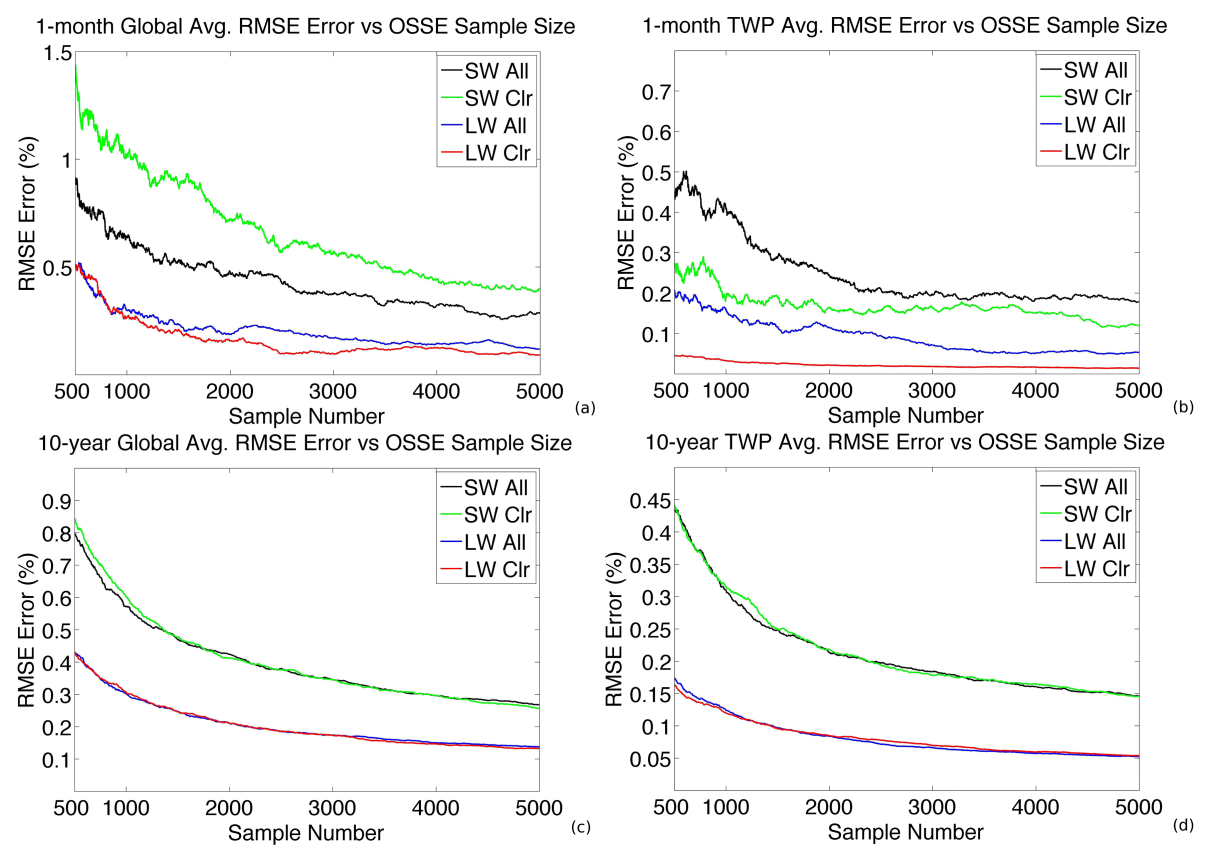

Figure 5. (a) RMSE vs. number of randomly sampled grid cells for January 2000 global average. (b) Same as (a) but for a tropical western Pacific region $\left(10^{\circ} \mathrm{S}-10^{\circ} \mathrm{N}, 100-150^{\circ} \mathrm{E}\right)$. (c) Same as (a) but for decadal average 2000-2009. (d) Same as (b) but for the decadal average 2000-2009.

comparison, and the contrasting performance of the OSSE in the visible and infrared windows and near-infrared water vapour overtone bands, and mid-infrared vibration-rotation bands provide an indication for the potential benefit for the construction of combined shortwave and long-wave spectral fingerprints (e.g. Leroy and Anderson, 2010; Huang et al., $2010 \mathrm{~b}$ ) of climate change, without the degeneracy of signals from low-clouds and surface temperature.

\section{Computational expense}

The computational expense of the OSSE described here is extreme, even for advanced supercomputers, and requires a careful consideration of system queuing priorities to balance throughput with resource request size. Furthermore, even the expense of the COSP simulators, which is considerably less than the OSSE described herein, is prohibitive.

For reference purposes, we find that, using MODTRAN, for a 26-level atmosphere, each all-sky shortwave spectrum calculation, which includes 16 sub-column calls for the cloud overlap approximation, requires $184 \mathrm{CPU}$ s while each longwave spectrum calculation, which also includes 16 subcolumn calls, requires 17.6 CPU s on the NASA HEC resources. The computational expense scales with the number of levels and sub-column calls. More optimized radiative transfer codes such as Principal Component Radiative Transfer Model (PCRTM) (Liu et al., 2006) can achieve a speed-up of at least 1 order of magnitude in the shortwave and 2 orders of magnitude in the long wave.
In preparation for the large number of simulations that will likely be submitted to the CMIP6 archive, there is a pressing need to consider how observational simulators can have reduced computational expense. We therefore consider how future OSSEs may perform spatial sampling to achieve tolerable radiometric accuracy with fewer radiative transfer calls. Figure 5a-d show that global and regional averages can be obtained by randomly sampling grid boxes and then performing radiative transfer calculations. This will produce a level of radiometric error that is less $2 \%$ for global average and $1 \%$ for tropical western Pacific regional average, which is consistent with the CLARREO mission specification (Wielicki et al., 2013) with 2 orders of magnitude fewer calculations. These results imply that inline satellite simulation, may be tractable for CMIP5 and CMIP6 models where climatological averages are desired.

\section{Discussion}

This paper has introduced a software framework that is capable of simulating the shortwave and long-wave TOA spectral signatures of the climate change diagnosed from projections from global climate and Earth system models. This represents a contribution to the growing literature around instrument emulation since attainment of this consistency requires particular attention to, and extensive validation of, the issues of consistent treatment of cloud overlap/geometry, cloud condensate, the spectral optical properties of cloud condensate, and the cloud thermodynamic state. 
The reason why this consistency is critically important is that departures of the hyperspectral simulated signal against observations (e.g. SCIAMACHY and AIRS) can then be used directly to check the cloud physics in the model, and in turn we can examine whether broadband cloud feedbacks to climate change have a particularly large AND UNIQUE spectral signature that would be particularly useful for early detection efforts.

The pan-spectral simulations span from the near-UV to the far-infrared and indicate a rich level of information content. Long-term measurements of changes in these quantities will capture many of the climate change processes and the relationships between these processes that are sources of uncertainty in climate models. They also indicate that the shortwave measurements are much more spatially heterogeneous than the long-wave measurements, so analysis of globally averaged changes in shortwave spectra is less suited towards diagnosing the processes that contribute to spectral changes than detailed examination of spatially resolved differences.

The ultimate goal of this research is to understand both how climate change alters the evolution of the Earth's topof-atmosphere shortwave reflectance and long-wave radiance spectra and determine whether spectral measurements enhance our detection and attribution of climate change. The pan-spectral OSSE described here will enable formal comparisons between models and a broad suite of planned and existing instrumentation, and will help establish observational metrics for differentiating between climate models according to specific processes. This may also enhance the current efforts to utilise the highly regularised climate model reporting framework of the CMIP5 to simulate specific instrumentation through the Observational Simulator Package (COSP) (Bodas-Salcedo et al., 2011). At the time of writing, the COSP framework (version 1.3.1) currently has ISCCP, MODIS, CloudSat, and CALIPSO instrument emulators. It can be linked with the Radiative Transfer for Television Infrared Observation Satellite Operational Vertical Sounder (RTTOV) (Saunders et al., 1999), which is a hyperspectral mid-infrared simulator, but that package has only been developed for clear-sky applications. Regardless, there is a critical need to develop the methodology to utilise the spectral dimension to gauge model performance. Recent works by Roberts et al. $(2011,2013)$ provide a path forward for how this can be undertaken quantitatively using principal components, and these tools may be helpful for the modelling community for narrowing the range in reported shortwave feedback.

A primary challenge to the utilisation of instrument simulators for model and measurement-model intercomparison is their large computational expense. For pan-spectral simulators, the expense is even more significant, with over $70 \%$ arising from the shortwave simulation. However, it should be noted that we found a contrast between the visible and near-infrared response to climate change, with the former largely controlled by spectrally flat features and the latter controlled by the interaction between clouds, aerosols, water vapour, and greenhouse gases. Spectral resolution is required to capture those interactions in the near-infrared. Moreover, Roberts et al. (2011) showed that the principal component spectrum from SCIAMACHY measurements changed significantly between 25 and $100 \mathrm{~nm}$ full-width half-max (FWHM) resolution, suggesting that information about shortwave processes requires dozens of channels, but not thousands. The computational expense can be lowered with ultra-fast radiative transfer methods (e.g. Liu et al., 2006). Alternatively, regional calculations may be considered for addressing those regions that contribute most significantly to climate sensitivity divergence (Armour et al., 2013). We also demonstrate that global and regional averages can be obtained with acceptable levels of radiometric error via simulations based on random grid-box sampling. This approach does have the potential to encompass a large number of existing and proposed measurement concepts. It is much more of a challenge to use narrow-band simulators to explore the value of new mission concepts.

For competent simulation, it is critical that model intercomparison projects, such as those of CMIP5, archive the fields necessary to perform offline diagnostic radiative transfer across the electromagnetic spectrum. This includes the three-dimensional thermodynamic, gaseous, and condensate structure of the atmosphere, and land emission and reflectance at sub-daily timescales. The Cloud Feedback Model Intercomparison Project (Bony et al., 2011) archived these fields for snapshots of several experiments associated with CMIP5, but the level of participation by the modelling centres was less than for the CMIP5 Tier 1 experiments including RCP8.5.

Spectra can be a very important tool for measurement model intercomparison, but OSSE development needs to be expanded to consider existing hyperspectral data records, which contain numerous indicators of processes that control the Earth's energy balance. At the time of writing of this paper, the data record from AIRS is over 11 years long, the IASI record is over 7 years long, and the SCIAMACHY record is over 10 years long. These decadal length records provide an opportunity to test present-day climate model performance in multiple ways that cannot be easily be adjusted with problematic tuning (Mauritsen et al., 2012) and can therefore be strict constraints for model development and testing. However, the challenges that have faced other long-term satellite data record analyses (Norris, 2007; Clement et al., 2009; Spencer and Christy, 1992; Fu and Johanson, 2004; Seidel et al., 2011) must be considered. While orbit and calibration are considerably less problematic for newer instrumentation, the climate quality of the instantaneous retrievals must be established. This pan-spectral simulation capability may also be applicable to recent efforts by CLimate Absolute Radiance and Refractivity Observatory (CLARREO) and GEOstationary Coastal and Air Pollution Events (GEO-CAPE) to develop the pan-spectral measurements in order to answer 
questions related to the processes that contribute to TOA atmospheric energetics and also the evolution of tropospheric chemistry.

The community should consider how the advent of panspectral measurements may have the potential to detect climate change and to distinguish which climate models produce more realistic projections, sooner than is possible with conventional broadband instruments (Feldman et al., 2013). Spectral empirical orthogonal functions may accelerate this ability to distinguish models even further by exploiting spectral redundancy to minimise noise and discern spectral multipole features less readily detected with broadband instruments. Pan-spectral techniques can then be used to detect low-cloud feedbacks sooner and with greater accuracy than broadband or spectral infrared techniques alone. Optimal detection techniques (e.g. Newchurch et al., 2003; Leroy and Anderson, 2010) are critical to establishing how the hyperspectral dimension can be utilised to detect climate change and assess models.

Acknowledgements. Funding for this research was supported by NASA grants NNX10AK27G, and NNX11AE65G and NASA High-End Computing grants SMD-08-0999, SMD-09-1397, and SMD-10-1799. This work was also supported by Contractor Supporting Research (CSR) funding from Berkeley Lab, provided by the Director, Office of Science, of the U.S. Department of Energy under contract no. DE-AC02-05CH11231. The following individuals also contributed: David Young, Bruce Wielicki, and Rosemary Baize of the NASA Langley Research Center, Tsengdar Lee of the NASA Science Mission Directorate, Lex Berk of Spectral Sciences, Inc., and four anonymous reviewers.

Edited by: F. O’Connor

\section{References}

Andrews, T., Gregory, J. M., Webb, M. J., and Taylor, K. E.: Forcing, feedbacks and climate sensitivity in CMIP5 coupled atmosphere-ocean climate models, Geophys. Res. Lett,, 39, L09712, doi:10.1029/2012GL051607, 2012.

Armour, K. C., Bitz, C. M., and Roe, G. H.: Time-Varying Climate Sensitivity from Regional Feedbacks, J. Climate, 26, 4518-4534, doi:10.1175/jcli-d-12-00544.1, 2013.

Arnold Jr., C. P. and Dey, C. H.: Observing-systems simulation experiments: Past, present, and future, B. Am. Meteorol. Soc., 67, 687-695, 1986.

Aumann, H. H., Chahine, M. T., Gautier, C., Goldberg, M. D., Kalnay, E., McMillin, L. M., Revercomb, H., Rosenkranz, P., Smith, W., Staelin, D., Strow, L., and Susskind, J.: AIRS/AMSU/HSB on the Aqua mission: Design, science objectives, data products, and processing systems, IEEE T. Geosci. Remote, 41, 253-264, 2003.

Berk, A., Anderson, G. P., Acharya, P. K., Bernstein, L. S., Muratov, L., Lee, J., Fox, M., Adler-Golden, S. M., Chetwynd, J. M., Hoke, M. L., Lockwood, R. B., Gardner, J. A., Cooley, T.
W., Borel, C. C., and Lewis, P. E.: MODTRAN 5: a reformulated atmospheric band model with auxiliary species and practical multiple scattering options: update, in: Defense and Security, 662-667, International Society for Optics and Photonics, doi:10.1117/12.578758, 2005.

Bodas-Salcedo, A., Webb, M. J., Bony, S., Chepfer, H., Dufresne, J.-L., Klein, S. A., Zhang, Y., Marchand, R., Haynes, J. M., Pincus, R., and John, V. O.: COSP: Satellite simulation software for model assessment, B. Am. Meteorol. Soc., 92, 1023-1043, 2011.

Bony, S., Webb, M., Bretherton, C., Klein, S. A., Siebesma, P., Tselioudis, G., and Zhang, M.: CFMIP: Towards a better evaluation and understanding of clouds and cloud feedbacks in CMIP5 models, CLIVAR Exchanges, 56, 20-22, 2011.

Bovensmann, H., Burrows, J. P., Buchwitz, M., Frerick, J., Noël, S., Rozanov, V. V., Chance, K. V., and Goede, A. P. H.: SCIAMACHY: Mission objectives and measurement modes, J. Atmos. Sci., 56, 127-150, 1999.

Clement, A. C., Burgman, R., and Norris, J. R.: Observational and model evidence for positive low-level cloud feedback, Science, 325, 460-464, 2009.

Collins, W. D., Bitz, C. M., Blackmon, M. L., Bonan, G. B., Bretherton, C. S., Carton, J. A., Chang, P., Doney, S. C., Hack, J. J., Henderson, T. B., Kiehl, J. T., Large, W. G., McKenna, D. S., Santer, B. D., and Smith, R. D.: The Community Climate System Model: CCSM3, J. Climate, 19, 2122-2143, 2006 a.

Collins, W. D., Ramaswamy, V., Schwarzkopf, M. D., Sun, Y., Portmann, R. W., Fu, Q., Cassanova, S. E. B., Dufresne, J.-L. , Fillmore, D. W., Forster, P. M. D., Galin, V. Y., Gohar, L. K., Ingram, W. J., Kratz, D. P., Lefebvre, M.-P., Li, J., Marquet, P., Oinas, V., Tsushima, Y., Uchiyama, T., and Zhong, W. Y.: Radiative forcing by well-mixed greenhouse gases: Estimates from climate models in the Intergovernmental Panel on Climate Change (IPCC) Fourth Assessment Report (AR4), J. Geophys. Res.-Atmos., 111, D14317, doi:10.1029/2005JD006713, 2006b.

Feldman, D. R., Algieri, C. A., Ong, J. R., and Collins, W. D.: CLARREO shortwave observing system simulation experiments of the twenty-first century: Simulator design and implementation, J. Geophys. Res.-Atmos., 116, D10107, doi:10.1029/2010JD015350, 2011a.

Feldman, D. R., Algieri, C. A., Collins, W. D., Roberts, Y. L., and Pilewskie, P. A.: Simulation studies for the detection of changes in broadband albedo and shortwave nadir reflectance spectra under a climate change scenario, J. Geophys. Res.-Atmos., 116, D24103, doi:10.1029/2011JD016407, 2011b.

Feldman, D. R., Coleman, D. M., and Collins, W. D.: On the Usage of Spectral and Broadband Satellite Instrument Measurements to Differentiate Climate Models with Different Low-Cloud Feedback Strengths, J. Climate, 26, 6561-6574, doi:10.1175/JCLID-12-00378.1, 2013.

Flato, G., Marotzke, J., Abiodun, B., Braconnot, P., Chou, S. C., Collins, W., Cox, P., Driouech, F., Emori, S., Eyring, V., Forest, C., Gleckler, P., Guilyardi, E., Jakob, C., Kattsov, V., Reason, C., and Rummukainen, M.: Evaluation of Climate Models, in: Climate Change 2013: The Physical Science Basis, Contribution of Working Group I to the Fifth Assessment Report of the Intergovernmental Panel on Climate Change, edited by: Stocker, T. F., Qin, D., Plattner, G.-K., Tignor, M., Allen, S. K., Boschung, J., Nauels, A., Xia, Y., Bex, V., and Midgley, P. M., Cambridge Uni- 
versity Press, Cambridge, United Kingdom and New York, NY, USA, 2013.

$\mathrm{Fu}$, Q. and Johanson, C. M.: Stratospheric influences on MSUderived tropospheric temperature trends: A direct error analysis, J. Climate,17, 4636-4640, doi:10.1175/JCLI-3267.1, 2004.

Goody, R., Anderson, J., and North, G.: Testing climate models: An approach, B. Am. Meteorol. Soc., 79, 2541-2549, 1998.

Hansen, J. E. and Travis, L. D.: Light scattering in planetary atmospheres, Space Sci. Rev., 16, 527-610, 1974.

Hansen, J. E., Nazarenko, L., Ruedy, R., Sato, M., Willis, J., Del Genio, A., Kock, D., Lacis, A., Lo, K., Menon, S., Novakov, T., Perlwitz, J., Russell, G., Schmidt, G., and Tausnev, N.: Earth's energy imbalance: Confirmation and implications, Science, 208, 1431-1435, 2005.

Huang, Y. and Ramaswamy, V.: Evolution and trend of the outgoing longwave radiation spectrum, J. Climate, 22, 4637-4651, 2009.

Huang, Y., Ramaswamy, V., Huang, X., Fu, Q., and Bardeen, C.: A strict test in climate modeling with spectrally resolved radiances: GCM simulation versus AIRS observations, Geophys. Res. Lett, 34, L24707, doi:10.1029/2007GL031409, 2007.

Huang, Y., Leroy, S. S., and Anderson, J. G.: Determining Longwave Forcing and Feedback Using Infrared Spectra and GNSS Radio Occultation, J. Climate, 23, 6027-6035, 2010a.

Huang, Y., Leroy, S., Gero, J., Dykema, J., and Anderson, J.: Separation of long-wave climate feedbacks from spectral observations, J. Geophys. Res.-Atmos., 115, D07104, doi:10.1029/2009JD012766, 2010b.

Jin, Z., Wielicki, B. A., Loukachine, C., Charlock, T. P., Young, D., and Noël, S.: Spectral kernel approach to study radiative response of climate variables and interannual variability of reflected solar spectrum, J. Geophys. Res.-Atmos., 116, D10113, doi:10.1029/2010JD015228, 2011.

Jones, C. D., Hughes, J. K., Bellouin, N., Hardiman, S. C., Jones, G. S., Knight, J., Liddicoat, S., O’Connor, F. M., Andres, R. J., Bell, C., Boo, K.-O., Bozzo, A., Butchart, N., Cadule, P., Corbin, K. D., Doutriaux-Boucher, M., Friedlingstein, P., Gornall, J., Gray, L., Halloran, P. R., Hurtt, G., Ingram, W. J., Lamarque, J.-F., Law, R. M., Meinshausen, M., Osprey, S., Palin, E. J., Parsons Chini, L., Raddatz, T., Sanderson, M. G., Sellar, A. A., Schurer, A., Valdes, P., Wood, N., Woodward, S., Yoshioka, M., and Zerroukat, M.: The HadGEM2-ES implementation of CMIP5 centennial simulations, Geosci. Model Dev., 4, 543-570, doi:10.5194/gmd-4-543-2011, 2011.

Kay, J. E., Hillman, B. R., Klein, S. A., Zhang, Y., Medeiros, B., Pincus, R., Gettelman, A., Eaton, B., Boyle, J., Marchand, R., and Ackerman, T. P.: Exposing Global Cloud Biases in the Community Atmosphere Model (CAM) Using Satellite Observations and Their Corresponding Instrument Simulators, J. Climate, 25, 5190-5207, doi:10.1175/JCLI-D-11-00469.1, 2012.

Kiehl, J. T. and Trenberth, K. E.: Earth's annual global mean energy budget, B. Am. Meteorol. Soc., 78, 197-208, 1997.

Kiehl, J. T., Hack, J. J., and Briegleb, B. P.: The simulated Earth radiation budget of the National Center for Atmospheric Research community climate model CCM2 and comparisons with the Earth Radiation Budget Experiment (ERBE), J. Geophys. Res., 99, 20815-20827, doi:10.1029/94JD00941, 1994.

Leroy, S. and Anderson, J.: Optimal Detection of Regional Trends Using Global Data, J. Climate, 23, 4438-4446, doi:10.1175/2010JCLI3550.1, 2010.
Leroy, S., Anderson, J., Dykema, J., and Goody, R.: Testing climate models using thermal infrared spectra, J. Climate, 21, 1863$1875,2008$.

Liu, X., Smith, W. L., Zhou, D. K., and Larar, A.: Principal component-based radiative transfer model for hyperspectral sensors: theoretical concept, Appl. Optics, 45, 201-209, 2006.

Loeb, N. G., Wielicki, B. A., Doelling, D. R., Smith, G. L., Keyes, D. F., Kato, S., Manalo-Smith, N., and Wong, T.: Toward Optimal Closure of the Earth's Top-of-Atmosphere Radiation Budget, J. Climate, 22, 748-766, 2009.

Mauritsen, T., Stevens, B., Roeckner, E., Crueger, T., Esch, M., Giorgetta, M., Haak, H., Jungclaus, J., Klocke, D., Matei, D., Mikolajewicz, U., Notz, D., Pincus, R., Schmidt, H., and Tomassini, L.: Tuning the climate of a global model, J. Adv. Model. Earth Sy., 4, M00A01, doi:10.1029/2012MS000154, 2012.

Meehl, G. A., Washington, W. M., Santer, B. D., Collins, W. D., Arblaster, J. M., Hu, A., Lawrence, D. M., Teng, H., Buja, L. E., and Strand, W. G.: Climate Change Projections for the TwentyFirst Century and Climate Change Commitment in the CCSM3, J. Climate, 19, 2597-2616, 2006.

Meehl, G. A., Moss, R., Taylor, K. E., Eyring, V., Stouffer, R. J., Bony, S., and Stevens, B.: Climate Model Intercomparison: Preparing for the Next Phase, Eos, Trans. AGU, 95, 77-78, 2014.

Morcrette, J.-J.: Radiation and Cloud Radiative Properties in the European Centre for Medium Range Weather Forecasts Forecasting System, J. Geophys. Res., 96, 9121-9132, doi:10.1029/89JD01597, 1991.

Newchurch, M. J., Yang, E. S., Cunnold, D. M., Reinsel, G. C., Zawodny, J. M., and Russell, J. M.: Evidence for slowdown in stratospheric ozone loss: First stage of ozone recovery, J. Geophys. Res.-Atmos., 108, 4507, doi:10.1029/2003JD003471, 2003.

Norris, J. R.: Observed Interdecadal Changes in Cloudiness: Real or Spurious?, in: Climate Variability and Extremes during the Past 100 Years, 169-178, Springer, Netherlands, 2007.

Oreopoulos, L. and Mlawer, E.: MODELING: The Continual Intercomparison of Radiation Codes (CIRC) Assessing Anew the Quality of GCM Radiation Algorithms, B. Am. Meteorol. Soc., 91, 305-310, 2010.

Pincus, R., Platnick, S., Ackerman, S. A., Hemler, R. S., and Patrick Hofmann, R. J.: Reconciling Simulated and Observed Views of Clouds: MODIS, ISCCP, and the Limits of Instrument Simulators, J. Climate, 25, 4699-4720, doi:10.1175/JCLI-D-1100267.1, 2012.

Roberts, Y. L., Pilewskie, P., and Kindel, B. C.: Evaluating the observed variability in hyperspectral Earth-reflected solar radiance, J. Geophys. Res.-Atmos., 116, D24119, doi:10.1029/2011JD016448, 2011.

Roberts, Y. L., Pilewskie, P., Kindel, B. C., Feldman, D. R., and Collins, W. D.: Quantitative comparison of the variability in observed and simulated shortwave reflectance, Atmos. Chem. Phys., 13, 3133-3147, doi:10.5194/acp-13-3133-2013, 2013.

Saunders, R., Matricardi, M., and Brunel, P.: An improved fast radiative transfer model for assimilation of satellite radiance observations, Q. J. Roy. Meteor. Soc., 125, 1407-1425, 1999.

Schaaf, C. B., Gao, F., Strahler, A. H., Lucht, W., Li, X., Tsang, T., Strugnell, N. C., Zhang, X., Jin, Y., Muller, J.-P., Lewis, P., Barnesly, M., Hobson, P., Disney, M., Roberts, G., Dunderdale, M., 
Doll, C., d'Entremont, R. P., Hu, B., Liang, S., Privette, J. L., and Roy, D.: First operational BRDF, albedo nadir reflectance products from MODIS, Remote Sens. Environ., 83, 135-148, 2002.

Seidel, D. J., Gillett, N. P., Lanzante, J. R., Shine, K. P., and Thorne, P. W.: Stratospheric temperature trends: Our evolving understanding, Wiley Interdisc. Rev. Clim. Change, 2, 592-616, 2011.

Siméoni, D., Singer, C., and Chalon, G.: Infrared atmospheric sounding interferometer, Acta Astronaut., 40, 113-118, 1997.

Slingo, A.: A GCM parameterization for the shortwave radiative properties of clouds, J. Atmos. Sci., 46, 1419-1427, 1989.

Space Studies Board: Earth Science and Applications from Space: National Imperatives for the Next Decade and Beyond, National Academies Press, Washington, DC, USA, 456 pp., 2007.

Spencer, R. W. and Christy, J. R.: Precision and radiosonde validation of satellite gridpoint temperature anomalies. Part II: A tropospheric retrieval and trends during 1979-90, J. Climate, 5, 858-866, 1992.

Taylor, K. E., Stouffer, R. J., and Meehl, G. A.: An overview of CMIP5 and the experiment design, B. Am. Meteorol. Soc., 93, 485-498, 2012.

Van Vuuren, D. P., Edmonds, J., Kainuma, M., Riahi, K., Thomson, A., Hibbard, K., Hurtt, G., Kram, T., Krey, V., Lamarque, J.-F., Masui, To., Meinshausen, M., Nakicenovic, N., Smith, S., and Rose, S. K.: The representative concentration pathways: an overview, Climatic Change, 109, 5-31, 2011.
Wan, Z. and Zhao-Liang, L.: A physics-based algorithm for retrieving land-surface emissivity and temperature from EOS/MODIS data, IEEE T. Geosci. Remote, 35, 980-996, 1997.

Watanabe, M., Suzuki, T., O'ishi, R., Komuro, Y., Watanabe, S., Emori, S., Takemura, T., Chikira, M., Ogura, T., Sekiguchi, M., Takata, K., Yamazaki, D., Yokohata, T., Nozawa, T., Hasumi, H., Tatebe, H., and Kimoto, M.: Improved climate simulation by MIROC5: mean states, variability, and climate sensitivity, J. Climate, 23, 6312-6335, 2010.

Wielicki, B. A., Charlock, T. P., Doelling, D. R., Kratz, D. P., Loeb, N. G., Minnis, P., Priestley, K. J., and Young, D. F.: CERES radiation budget accuracy overview, Preprints, 12th Conf. Atmospheric Radiation, 13 July 2006, Madison, WI, B. Am. Meteorol. Soc., 9, 1, 2006.

Wielicki, B. A., Young, D. F., Mlynczak, M. G., Thome, K. J., Leroy, S., Corliss, J., Anderson, J. G., Ao, C., Bantges, R., Best, F., Bowman, K., Brindley, H., Butler, J. J., Collins, W., Dykema, J. A., Doelling, D. R., Feldman, D. R., Fox. N., Huang, X., and Holz, R.: Achieving Climate Change Absolute Accuracy in Orbit, B. Am. Meteorol. Soc., 94, 1519-1539, doi:10.1175/BAMSD-12-00149.1, 2013. 